Nutr. Metabol. 1973;15:314

\title{
Book Review - Buchbesprechung - Livre nouveau
}

G. Labò, L. Barbara and N. Melchoinda (ed.): La Via Metabolica Dell’Aterogenesi. Proc. 1st Symp. on Physiopathology of Nutrition and Dietetics. Patron, Bologna 1972. 869 pp.; Lit. 18,000 .

In this book of more than 800 pages are the papers presented at the First Symposium on Metabolic Aspects of Atherosclerosis held in Bologna from the 16th to 18th of June 1972. Most of the papers are in Italian, some are in French and some in English, but for all articles there are summaries in the three languages. In the first part of the Symposium the metabolic problems in atherosclerosis - particularly obesity, diabetes, carbohydrate and lipid metabolism - have been covered. The second part is dealing with the nutritional problems, giving main consideration to the effects of various carbohydrates on serum lipids. The therapeutic problems were examined in the third part. The pharmacologic and metabolic actions of biguamides were initially dealt with and then prostaglandins, clofi-brate and other drugs generally used in the therapy of obesity, diabetes and hyperlipidemia were discussed.

The Symposium was an interesting one, but there were too many papers in such a short time. Completely missed were the results from epidemiological and prevention studies.

F. Fidanza, Perugia

Varia

Continuing Education in Health Sciences

University of California, San Francisco, Calif.

Cardiovascular Physiology, October 13-14 and 20-21,1973; Physiology of Respiration,

November 10-11, 1973, and Kidney Function, December 1-2, 1973.

These courses have been planned for electronic technicians and engineers who work in biological laboratories, as well as nurses and other paramedical professionals with direct patient responsibilities. The programs are open to any person desiring to review or upgrade his or her knowledge, or to gain some understanding of lung, kidney and cardiac function. These programs are presented by Continuing Education in Health Sciences, University of California, San Francisco, Calif. Upon request, a certificate of completion will be issued at the conclusion of each program.

Instructor. L.S.Lukin, Ph.D., Associate Professor of Physiology, University of the Pacific School of Dentistry; Lecturer in Physiology, Curriculum in Physical Therapy, University of California School of Medicine, San Francisco, Calif.

Application for enrollment. Mail to: Department M, Continuing Education in Health Sciences, Room 570U, University of California, San Francisco, CA 94143 (USA). Check payable to: The Regents of the University of California. 